Proceedings of the 2011 Winter Simulation Conference

S. Jain, R.R. Creasey, J. Himmelspach, K.P. White, and M. Fu, eds.

\title{
UTILITY RESOURCE PLANNING USING MODULAR SIMULATION AND OPTIMIZATION
}

\author{
Juan Sáenz Corredor \\ Nurcin Celik \\ Shihab Asfour \\ The University of Miami \\ 1251 Memorial Drive \\ Coral Gables, FL 33146, USA
}

\author{
Young-Jun Son \\ The University of Arizona \\ 1127 East James E. Rogers Way \\ Tucson, AZ 85721, USA
}

\begin{abstract}
Electric utility resource planning traditionally focuses on conventional energy supplies. Nowadays, planning of renewable energy generation and its storage has become equally important due to the growth in demand, insufficiency of natural resources, and policies for low carbon footprint. We propose to develop a simulation based decision making framework to determine the best possible combination of investments for electric power generation and storage capacities. The proposed tool involves a combined continuousdiscrete modular modeling approach for processes of different nature within this complex system, and will aid utility companies in resource planning via multi-objective optimization in a realistic simulation environment. The distributed power system considered has four components including energy generation, storage, transmission, and electricity demand. The proposed approach has been demonstrated for the electric utility resource planning at a scale of the state of Florida.
\end{abstract}

\section{INTRODUCTION}

Conventionally, the long-term planning of electric power systems focuses on the determination of the operational capacities of fossil fuel based energy generation systems. However, estimates are that conventional sources of energy can only meet our energy demands for another 50 to 70 years; and the world has turned to hybrid conventional-renewable energy sources as the solution. Stakeholders of electric utility planning seek ways to involve renewable energy in satisfying our energy needs in the upcoming decades.

Electricity production is the major source of most emissions of sulfur oxides (SOx), carbon dioxide (CO2), and nitrogen oxides (NOx) which are a cause of acid rain, contribute to global warming and to the formation of smog, respectively. Renewable energy has a lower environmental impact and will reduce the emission of greenhouse gases (GHG) as its employment increases. Its sources are free, sustainable and have no associated purchasing costs. Hence, the involvement of renewable sources in electric power generation at the utility scale is inevitable, and capacities of various kinds of renewable energy generation and energy storage systems, must be considered in line with capacities of the conventional generation systems for the long term survival of the utilities while incurring optimum multi-criteria objectives given increased market competition. However, there are challenges for the implementation of an effective capacity planning at utility scale. Power systems are very large scale and complex, and the consequences of alternative strategic resource planning scenarios should be evaluated in an integrated way for the various stakeholders. The planning process is complicated by growing uncertainty due to load growth, resource availability, regulatory and economic environments, and rising environmental concerns; while the long term planning of power industry is considerably affected by competition in various sectors of the market.

In this study, we propose a novel continuous-discrete modular simulation and optimization framework to accurately estimate the capacity requirements of electric power generation and storage, involving conventional and renewable sources. The tool developed enables the various stakeholders of electric utili- 
ty resource planning to devise the best possible capacity plans, while saving computational resources and costs. The goal of the optimization model is to minimize the financial investment and operational cost of building, operating and maintaining the combined renewable and fossil fuel based energy generation systems, as well as minimizing the environmental impact, while meeting the electricity demand. The proposed framework is composed of four evaluation and one optimization modules. The generation module (G) captures the details and characteristics of the hybrid conventional-renewable energy generation in an electric power system. The storage module (S) captures the attributes of various energy storage systems such as NaS batteries, and compressed air energy storage (CAES). The transmission and distribution grid elements such as the step-up and step-down substations and inverters are included in the transmission module (T) and demand from industrial, commercial, transportation, and residential customers is captured in the demand module (D). The optimization module $(\mathrm{O})$ determines the best possible combination of investment options that will result in minimized cost and environmental impact. Continuous-discrete modeling methodologies are used in each module depending on the nature of the sub-system while metaheuristics are utilized for the solution mechanism of module O. Since previous efforts on the resource planning of electric utility systems at this scale and scope incorporating real data are infrequent, acquisition of realistic data has been an additional challenge to this study. The constructed tool is used to find an optimal investment policy of renewable and fuel-based generation and energy storage. It is also used to test the impacts of several factors such as, different conflicting objectives, demand growth, efficiencies in PV panels, wind turbines, fuel operating power plants, CAES, and batteries, and losses in transmission lines on the total cost of the integrated electric system. While the proposed tool has been demonstrated for the state of Florida, the framework is built generically to be adopted for other states, or countries.

\section{PROPOSED MODULAR SIMULATION AND OPTIMIZATION FRAMEWORK}

A continuous-discrete modular simulation and optimization framework was developed in this study as the most reasonable method for assessing the different options for creating a real system of a magnitude and cost at utility scale. Through the proposed modular simulation, the best capacities of different energy generation systems can be foreseen. Modular simulation allows for a great deal of modeling flexibility, costs significantly less, and provides savings in time, compared to its emulator counterparts. The proposed modular simulation was developed with an emphasis on credibility, which in turn resides in analytical models and well-established literature.

Several challenges exist while modeling the power grid system using the proposed approach. The distributions of the data as well as its associated variability need to be defined in order to model the demand, solar radiation, and wind speed with accuracy. Research has enabled us to obtain the correct parameters for GHG emissions, energy generation efficiency, and cost. The design, interactions and mechanics of an energy system like the one simulated had to be determined correctly.

In real energy systems, energy is produced continuously and instantly consumed, stored or grounded. This is simulated by discrete entities created with fixed inter-arrival times, and each entity contains energy relative to the power output of the source over the inter-arrival time. The entity is then sent to the grid and either stored, consumed or grounded. This approximation creates some difficulties in distributing the energy correctly since some entities have much more energy than others; by having significantly small inter-arrival times, the loss of precision of the model by this approximation is minimized. Figure 1 shows the overview of our continuous-discrete modular approach to model electric utility resource planning.

\subsection{Energy Generation Module (G)}

Module $G$ lets us model each subsystem with precision, without impacting the rest of the systems in the model. Submodule 1 models solar energy generation including the capacity and efficiency of the system as well as the solar irradiance. Submodule 2 models wind energy generation with the wind speed in addition to the capacity and efficiency of the system. Submodule 3 models coal fired generation considering the system's capacity, its GHG emissions and specifics regarding its efficiency. Submodule 4 provides the details of natural gas fired generation, by taking into account the impacts of using a combined cycle; 
while submodule 5 provides the details of oil fired generation. The energy generating systems included in this study are presented below with the inclusion of advantages and disadvantages specific to each system, and their applicability to the case of Florida. Figure 2 shows module G including the renewable energy generation and the fossil fuel energy generation submodules developed as part of the framework.

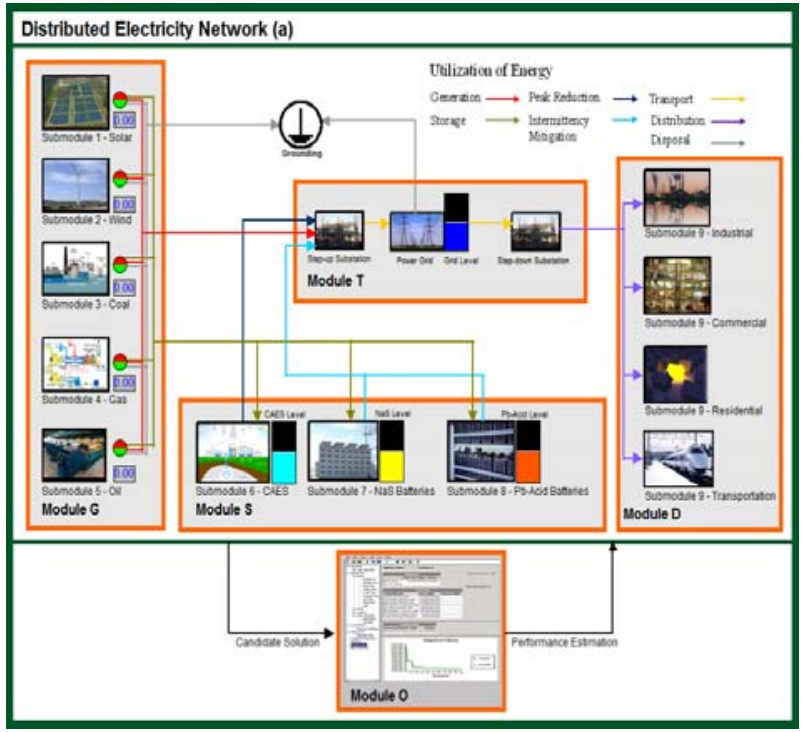

Figure 1: Overview of the proposed model

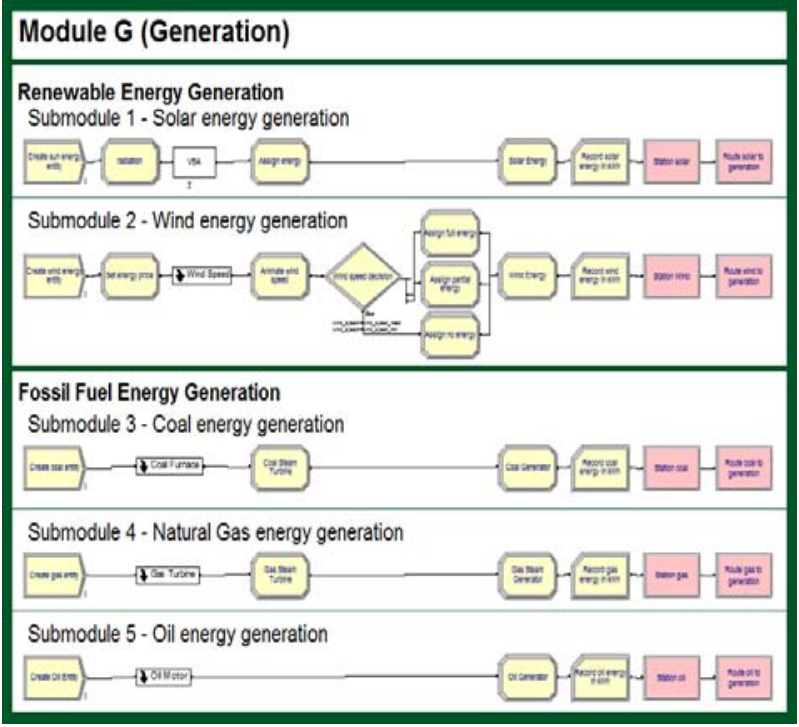

Figure 2: Energy generation Module G

\subsubsection{Solar Energy Generation}

Electricity generation from solar energy is renewable, clean, and silent. Photovoltaic (PV) devices are based on a modular technology that can be expanded and applied to almost any landscape and at various scales. Most commercially available solar panels have a 25 -year performance warranty with additional warranties up to 10-years for inverters and other components. However, PV generation heavily depends on solar irradiation which is not constant and depends on the specific location, time of the day, season, and weather conditions; affecting the energy that can be produced regardless of demand. Thus, solar energy systems give rise to the need for energy storage systems and for alternate energy generation systems, to ensure that the demand is met at all times (Dinçer 2011).

Florida is the second largest solar energy generating state in the U.S. The 25MW, DeSoto Solar Energy Center, is the largest solar PV plant in the country, with more than 90,500 solar panels. The Space Coast Solar Energy Center, has an estimated capacity of 10MW (FPL 2010) and there are plans regarding the construction of new solar PV farms. These actions taken to make Florida as green as possible have led us to select it for our study. The framework proposed in this study is built considering the realistic environmental conditions. Therefore, it incorporates the characteristics of the PV panels that are currently being used in solar farms in Florida, especially the SunPower E19/318 modules. These panels have a peak power of 318 watts, a voltage and current of 64.7 volts and 5.82 amperes; they are very efficient (19.5\%), measure 61.4" x 41.2", and their price is around \$2,000. PV devices are used to convert solar energy into electricity. The photoelectric effect is the emission of electrons from the surface of a metal exposed to sunlight, when this process is applied to millions of electrons, sunlight is converted to electricity. A solar panel's maximum electrical power $\left(P_{m}\right)$ is a function of its electrical efficiency $(\eta)$ and area $(A)$ and the solar irradiance $\left(G_{T}\right)$, as $P_{m}=\eta \times A \times G_{T}$ under standard test conditions (Skoplaki and Palyvos 2009).

This functionality of the PV devices is incorporated into the proposed framework, where entities are assigned a value for solar irradiance using a schedule that assigns irradiation corresponding to the particular hour of the year that is being simulated. Entities then enter a VBA element to assign a level to radiation, after which the energy and its costs are calculated using a variable that specifies the area of PV pan- 
els and their efficiency. In PV technology, to estimate the energy generation output correctly, the accuracy of solar irradiation input is critical. For this, we combine satellite-sensed data obtained from the National Renewable Energy Laboratory's (NREL) National Solar Radiation Database with the data obtained locally, capturing spatial and temporal variability of solar radiation specific to the Miami area. NREL collects solar irradiance data at the Miami International Airport and the Kendall-Tamiami Executive Airport, among many other sites. The spatial and temporal variability data is obtained from the University of Miami Industrial Assessment Center's (UMIAC) Kipp and Zonen CMP-11 pyranometer, located on the engineering building that has been programmed to record solar irradiance every minute, shown in Figure 3.
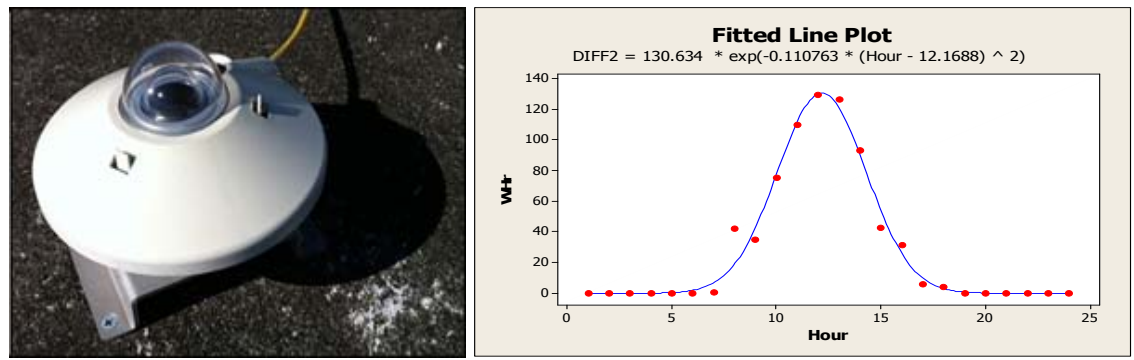

Figure 3: UM's CMP-11 pyranometer, and the data fit for the adjustment between $\mathrm{WHr}_{\mathrm{UM}}$ and $\mathrm{WHr}_{\mathrm{NREL}}$

The irradiation collected the University of Miami (UM), was used to determine the distribution that fits the best to the data as $W H r_{U M}=681.846 e^{-0.08373(H-12.674)^{2}}$, solar irradiation obtained from NREL has also been fitted the best to the equation given by $W_{H R E L}=557.157 e^{-0.08053(H-13.805)^{2}} . W H r$ is the solar irradiance in watt-hour per square meter and $H$ is the independent hour of the day. We found latency in the data collected by NREL comparing it to that collected at the UM. The comparison of the average radiation for the month of December shows that for UM's data, the maximum is at 12:00 PM, while for NREL's data the maximum radiation is at 1:00 PM. In order to mitigate the impact of latency in our framework, we adjusted our comparison by one hour to match the data from the two sources. After the adjustment, the comparison shows a negligible difference between the data sets, as shown in Figure 3 . The distribution of the differences between the data collected at the UM and the one from NREL has been found to be as $\operatorname{Diff}_{L}=130.634 e^{-0.11077(H-12.169)^{2}}$ where $\operatorname{Diff}_{L}$ is the value predicted for $W H r_{U M}-$ $W H r_{\text {NREL }}$ with a $R^{2}$ value of $98.0 \%$. In the framework, the solar irradiation is simulated using the satellite sensed data and the aforementioned fitted distributions for the adjusted difference. To this end we use the average of the satellite sensed data for each hour of the year, using the data from 2000 through 2005; then, we combine this with the distribution of the difference between the two sources in order to include the spatial temporal variability using $W H r_{U M}{ }^{*}(n)=\overline{W H r_{N R E L}}(n)+\operatorname{Diff}_{L}$ where $W H r_{U M}{ }^{*}(n)$ is the estimated solar irradiance for the $n^{\text {th }}$ hour of the year and $\overline{W H r_{N R E L}}(n)$ is the average of the satellite sensed irradiance for the $n^{\text {th }}$ hour of the year. The results are then used in the framework as irradiation input.

\subsubsection{Wind Energy Generation}

Wind energy is a renewable source of energy, that saves the environment from considerable amounts of pollutant emissions. Lifecycle $\mathrm{CO} 2$ emissions per unit of energy produced by a wind farm is estimated to be about $1 \%$ of that for coal plants (Akpinar et al. 2007). However, wind energy generation depends on wind availability, and since wind power is proportional to the third power of the wind speed, the effects of intermittency in wind speeds sharply influence the performance of the turbines (Zahedi 2011). Since wind power is so intermittent, its integration to a power grid poses threats to performance and raises the need for energy storage systems (Erdogdu 2009).

United States is the largest wind energy generating country with a capacity to generate $35,159 \mathrm{MW}$ (WWEA 2010). While there are no wind farms in Florida, FPL has proposed the St. Lucie wind energy project to build six wind turbines with a capacity of up to $13.8 \mathrm{MW}$ (FPL 2008). The turbines that are primarily considered for the St. Lucie wind energy project are the GE TC2 2.5-100. These turbines have a 
rated power of $2.3 \mathrm{MW}$, a rated wind speed of $12 \mathrm{~m} / \mathrm{s}$ a hub height of $85-100$ meters and a rotational speed of $14.1 \mathrm{rpms}$; and are the ones considered in the framework.

The mechanical power of a wind turbine is given by $P_{o}=1 / 2 \rho A V^{3}\left\{\left(1+V_{0} / V\right)\left[1-\left(V_{0} / V\right)^{2}\right] / 2\right\}$, where $P_{0}$ is the power generated by the turbine, $\rho$ is the density of the air, $A$ is the area swept by the blades, $V$ is the upstream wind velocity, and $V_{0}$ is the downstream wind velocity. The practical maximum power for a wind turbine is $P_{\max }=1 / 4 \rho A V^{3}$ (Patel 2006). In submodule 2, entities are assigned a wind speed according to the distribution of the wind speed for the particular month. Once an entity has an assigned wind speed, the model checks if it is sufficient to run the wind turbine at full capacity, partial capacity or not at all; and the energy is generated. In the model, the rated and minimum operating wind speeds are assumed to be 12 and $4 \mathrm{~m} / \mathrm{s}$.

In order to accurately estimate the wind speed, we used wind speed data collected by NREL for the years 2004 to 2006; at ten-minute intervals at NREL's 5131 site in North Carolina (NREL 2009). This data is a part of a project for the development of wind integration datasets that provide wind profiles for the U.S. and estimate the production from possible wind plants. NREL's 5131 station was chosen since the monthly average wind speed at this location is very close to that reported by FPL at the St. Lucie Wind Project, with only $14 \%$ difference on average; and it is the geographically closest location to the state of Florida. In this research, in order to estimate the typical wind speed, average wind speeds are obtained for each hour of the year. The data is then split into the different months in order to capture seasonal effects such as the typically higher wind speeds during the winter than during the summer. The disaggregated monthly data is fitted to the probability distributions incorporated into the framework shown in Table 1.

Table 1: Fitted distributions for monthly wind speed data

\begin{tabular}{|c|l|c|c|l|c|}
\hline Month & \multicolumn{1}{|c|}{ Fitted Distribution } & Sq. Error & Month & \multicolumn{1}{|c|}{ Fitted Distribution } & Sq. Error \\
\hline January & $\begin{array}{l}\text { 2+ Gamm (0.8, 7.45) } \\
\text { Mean: 7.96 Var: 4.38 }\end{array}$ & 0.004606 & July & $\begin{array}{l}\text { Norm (6.16, 1.68) } \\
\text { Mean: 6.16 Var: 2.81 }\end{array}$ & 0.001278 \\
\hline February & $\begin{array}{l}\text { Norm (7.74, 2.03) } \\
\text { Mean: 7.74 Var: 4.12 }\end{array}$ & 0.002476 & August & $\begin{array}{l}\text { Norm (5.79, 1.64) } \\
\text { Mean: 5.79 Var: 2.68 }\end{array}$ & 0.001109 \\
\hline March & $\begin{array}{l}\text { 1+14 Beta (5.58, 6.32) } \\
\text { Mean: 7.58 Var: 4.39 }\end{array}$ & 0.001959 & September & $\begin{array}{l}\text { 2+ Gamm (0.735, 6.76) } \\
\text { Mean: 6.97 Var: 3.37 }\end{array}$ & 0.001688 \\
\hline April & $\begin{array}{l}\text { Norm (8.44, 2.08) } \\
\text { Mean: 8.44 Var: 4.34 }\end{array}$ & 0.001701 & October & $\begin{array}{l}\text { 2+ Weib (4.9, 3.22) } \\
\text { Mean: 6.47 Var: 2.51 }\end{array}$ & 0.001375 \\
\hline May & $\begin{array}{l}\text { Mean: 7.10 Var: 3.56 } \\
\text { Meta (3.27, 3.09) }\end{array}$ & 0.000801 & November & $\begin{array}{l}\text { Norm (6.81, 1.87) } \\
\text { Mean: 6.81 Var: 3.51 }\end{array}$ & 0.002399 \\
\hline June & $\begin{array}{l}\text { Norm (6.38, 1.73) } \\
\text { Mean: 6.38 Var: 3.01 }\end{array}$ & 0.002372 & December & $\begin{array}{l}\text { 1 Weib (6.58, 3.52) } \\
\text { Mean: 7.08 Var: 4.94 }\end{array}$ & 0.002871 \\
\hline
\end{tabular}

\subsubsection{Fossil Fuel Energy Generation}

As of 2010, approximately $70 \%$ of the electricity generated in the U.S. is from fossil fuels (EIA 2010). Energy can be harvested from three major forms of fossil fuels: coal, oil, and natural gas. Coal is the most common fossil fuel in the U.S., and can be categorized by its amount of carbon. Oil is composed of decayed organic matter that occurs naturally in underground reservoirs. It is extracted as petroleum and refined for separation into its various components. The United States is the world's largest oil consumer. Natural gas is a mixture of hydrocarbons, it may be extracted from reservoirs or gas streams; or it can be separated from other petroleum products. In energy production, coal is usually pulverized and burned in a furnace with a boiler. The water is converted into steam and drives the turbines of a generator to produce electricity. Energy from oil is produced using reciprocating engines that drive power generators. Because of its transportation ease, oil is typically used to run power stations that are very difficult to connect to a power grid. Natural gas is used in combustion turbines that use the gas instead to turn the turbines that produce electricity. Combined cycle gas power plants like the one in Turkey Point in Florida, use excess heat to drive a steam-powered generator. The basic reaction that drives fossil fuel combustion converts fuel and oxygen into heat, $\mathrm{CO} 2$ and water. When the reaction uses oxygen from the air, it can be formulated as in $N_{2}+O=N O+N$ where the coefficients $\mathrm{x}$ and y depend on the fuel type. If the temperature of the reaction is high enough nitrogen may stop being inert and NOx are produced according to $C_{x} H_{y}+$ 
$(x+y / 4) \mathrm{O}_{2}+3.76(x+y / 4) N_{2}=x \mathrm{CO}_{2}+(y / 2) \mathrm{H}_{2} \mathrm{O}+3.76(x+y / 4) N_{2}$. Sulfur impurities in the fuel (mainly in coal) such as hydrogen sulfide $\mathrm{H}_{2} \mathrm{~S}$ or hydrosulfide ions $\mathrm{HS}^{-}$part of carbon chains lead to the formation of sulfur dioxide, as in $2 \mathrm{H}_{2} \mathrm{~S}+\mathrm{O}_{2}=\mathrm{S}_{2}+2 \mathrm{H}_{2} \mathrm{O}$.

The framework incorporates these processes in submodules 3, 4 and 5. In submodule 3, entities enter the furnace where the amount of coal used as well as the products of combustion, $\mathrm{CO} 2, \mathrm{NOx}, \mathrm{SOx}$ and heat are recorded. The heat is then inputted to the steam turbine, which is used in the electric generator to calculate the energy generated. Submodule 4 and submodule 5 have been modeled similarly to submodule 3 . The proposed framework incorporates the parameters of efficiency and emissions related to these processes in order to enhance its validity and represent the system as accurately as possible. The efficiency of coal power plants is assumed to be $35.1 \%$ based on the report by EIA (2007). The coal used is assumed to have a heat value of 9,902 Btu per pound and a sulfur content of $1.01 \%$ by weight (EIA 2010). A combined cycle power plant is assumed to have an efficiency of 59\% (Siemens 2010), and the heat value for the natural gas used in Florida is accepted as 1025 Btu per cubic foot (EIA 2010).

\subsection{Energy Storage Module (S)}

Energy storage systems, such as CAES and batteries, may be used to address problems such as fluctuations in demand, problems from intermittent generation or problems in reliability in electricity distribution among others (Eyer, Iannucci, and Corey 2004). Table 2 shows the key characteristics of some energy storage systems. CAES systems typically use an existing underground site and store gas at approximately 4-8MPa; they have high power capacity, large energy storage capacity, a quick start-up, a long storage period, and a relatively high efficiency (Beaudin et al. 2010). Succar and Williams (2008) show that the electrical output of a turbine in a CAES system is given by $E=\eta_{M} \eta_{G} \int_{0}^{t} m_{T} w_{T O T} d t$, where $E$ is the electrical output of the turbine, the integral is the work generated by the expansion of air and fuel in the turbine, $w_{\text {Tот }}$ is the total mechanical work generated in the process, $m_{T}$ is the air mass flow rate, $t$ is the time requires to deplete a full reservoir at full power, $\eta_{M}$ is the efficiency of the turbine and $\eta_{G}$ is the efficiency of the electric generator. A CAES system can use up to $67 \%$ less natural gas than a regular gas turbine generator (Gardner and Haynes 2007).

Table 2: Properties of energy storage systems

\begin{tabular}{|l|c|c|c|}
\hline \multicolumn{1}{|c|}{ Energy Storage System } & CAES & Pb-acid Battery & Na-S Battery \\
\hline Rated Capacity $(M W)$ & $5-300$ & $0-20$ & $0.05-8$ \\
\hline Rated Capacity Discharge $(h)$ & $1-24+$ & $0.0027-2+$ & $0.0027-2+$ \\
\hline Power Capacity Cost $(\$ / k W)$ & $2-50$ & $50-400$ & $300-500$ \\
\hline Response Time & Minutes & $<1 / 4$ cycle & $<1 / 4$ cycle \\
\hline Cycle Efficiency $(\%)$ & $70-89$ & $70-90$ & $75-90$ \\
\hline Cycle Life & $8-12,000$ & $500-1,000$ & $2,500-4,500$ \\
\hline Space Needs $\left(\mathrm{m}^{2} / \mathrm{kWh}\right)$ & 0.01 & 0.058 & 0.019 \\
\hline Life $($ years $)$ & $20-40$ & $5-15$ & $10-15$ \\
\hline
\end{tabular}

There are various types of batteries including Lead-acid, Nickel-Cadmium and Sodium-Sulfur (NaS). Lead-acid batteries have been used for more than 130 years, are the most common rechargeable electrochemical device, and are most commonly found in vehicles. They have low-cost, high reliability, strong surge capabilities, high efficiency, and are usually good for uninterruptible power supply and power quality (Chen et al. 2009). Lead-acid batteries have the reversible reaction given by $\mathrm{Pb}+\mathrm{PbO}_{2}+$ $2 \mathrm{H}_{2} \mathrm{SO}_{4}=2 \mathrm{PbSO}_{4}+2 \mathrm{H}_{2} \mathrm{O}$. NaS batteries are a very attractive emerging technology because they can be cycled 2500 times, have high power density, are efficient, and have a $600 \%$ rated pulse power capability that can last 30s (Dufo-Lopez, Bernal-Agustin and Dominguez-Navarro 2009). NaS batteries are environmentally friendly, they are sealed and allow no emissions during operation and more than $99 \%$ of their materials can be recycled. Sulfur batteries have the reaction equation given by $2 \mathrm{Na}+3 \mathrm{~S}=\mathrm{Na}_{2} \mathrm{~S}_{3}$.

The proposed framework models a CAES system (submodule 6), and a combination of Lead-acid and $\mathrm{NaS}$ battery systems (submodules 7 and 8). In submodule 6 the amount of energy stored is determined via the level of air in the CAES cavern as well as the efficiency of the compressor. When energy is requested from the CAES system such that the system needs to switch to the gas expansion stage, natural gas and 
the pressurized air are used to run a high pressure and a low pressure turbine. The turbines turn an electric generator that delivers the energy, and the energy level in the CAES system is adjusted after taking into account the operational efficiencies of these mechanisms.

Energy usage, and distribution, is captured via the step-up substation submodule that is attached to module S. As shown in Figure 4, the step-up substation submodule logs the total amount of energy that has been generated and decides the use of the energy from each generating entity between the grid, storage or grounding. If the energy in the grid is below a certain threshold, the energy from the entities is used to feed the grid; if not and there is available storage capacity in the storage systems, the energy from the energy generating entity is stored in the available means; if there is no available capacity for storage, then the excess energy is grounded. When energy is stored in the batteries, the system with the lowest amount of energy is used, just opposite to the case when the energy is being used. The level of energy in both battery systems is subject to their efficiency. Energy is stored in the CAES system only when the energy level in both battery systems is above predetermined thresholds, so when the energy is stored in the CAES system, the framework attempts to reduce the utilization of the oil and coal plants by reducing the current operational capacity by $10 \%$. This scale down mechanism is limited by a minimum runtime value for each of the plants which indicates the minimum frequency with which these operations may occur. When the energy is grounded, the scale down mechanism is activated for all the fossil fuel plants.

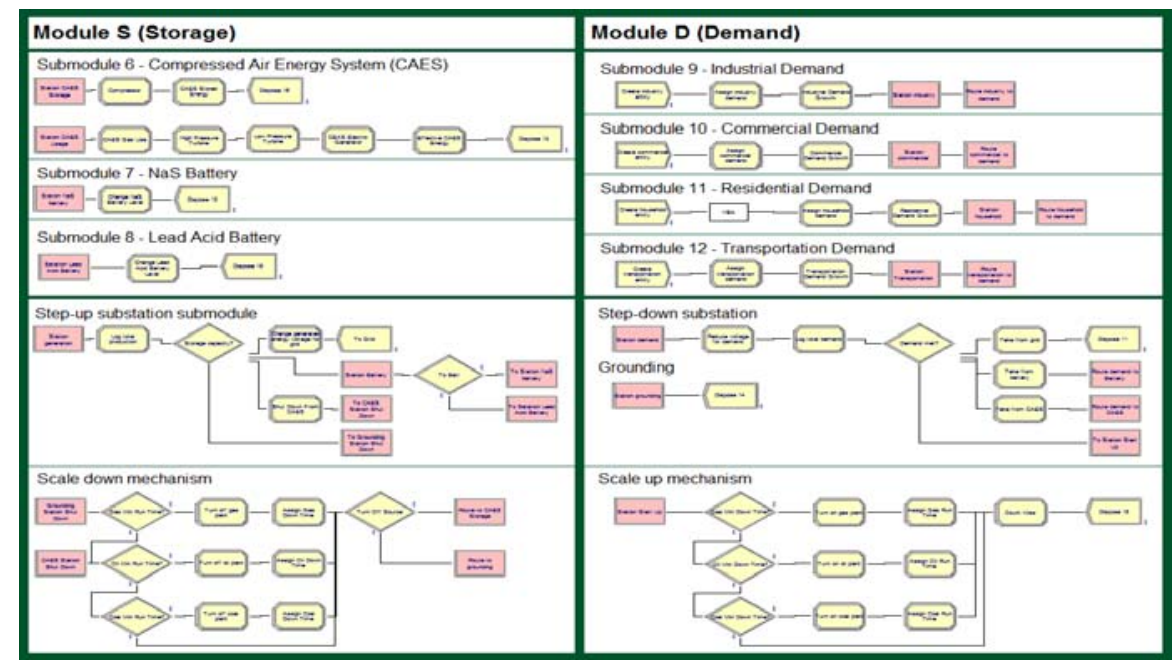

Figure 4: Storage (S) and demand (D) Modules

\subsection{Energy Demand Module (D)}

Energy is demanded by four major sectors: residential, commercial, industrial, and transportation; encompassing houses and mobile homes; firms not engaged in farming, manufacturing or transportation; the goods-producing sector; and electricity used for transportation, respectively (IEA 2010). The residential sector accounts for $36.43 \%$ of consumption, the commercial for $35.36 \%$, the industrial for $23.58 \%$ and the transportation sector for $0.21 \%$. Florida is the third largest electricity consuming state with $6.2 \%$ of the national total (EIA 2009). Here, Algorithm 1 is developed to enable accurate estimation of electricity demand by the various sectors. It allocates the hourly energy consumption rate by sector, considering the monthly energy consumption reported by the seven largest utility companies in the state of Florida (FPSC 2009), the average daily temperature recorded at the Miami International Airport, and the daily peak energy demand information from FPL. In addition to the temperature for each hour, the algorithm also distinguishes whether this day is a weekday, weekend, or a holiday. It should be noted here that the hourly temperature values also encompass the weather and the climate effect.

Figure 5 shows the operation of Algorithm 1 where $m$ is the index for the months of the year, $t$ is for hours, $y$ is for the consumption sectors, $z$ is for weekdays and weekends and $w$ is for holidays and non- 
holidays. $C H(t)$ is the energy consumption at a given hour $t, C M(t)$ is the total energy consumption of the month to which it belongs, $C F(t)$ is its consumption factor, $T(t)$ is its temperature, $T_{l}$ and $T_{h}$ are the temperatures at which electric heating and cooling start operating, $\mathrm{T}_{\mathrm{HS}}$ and $T_{C S}$ are the temperatures at which electric heating and cooling are set, $F_{E H}$ is the heating factor, $F_{E C}$ is the cooling factor, $F_{o}$ is the occupancy factor, $F_{H d}(w)$ is the holiday factor for holiday $w, F_{M}(m)$ is the month factor, and $F_{M N}(m)$ is the month normalization factor. The algorithm assigns each hour a consumption factor that is adjusted if the hour's temperature is below $T_{l}$ or above $T_{h}$; it is then multiplied by a series of parameters that take into account whether the hour is a peak consumption hour, part of a weekend or a weekday, the sector that is being modeled, and the impact of holidays. Each month's total consumption per sector is distributed according to the computed consumption factors. Algorithm 1 has been implemented using VBA and embedded into the simulation model with Arena schedules used to store the results of the algorithm. With these components we have exported the model to an Access database where the schedules are modified using the algorithm and imported back into Arena.
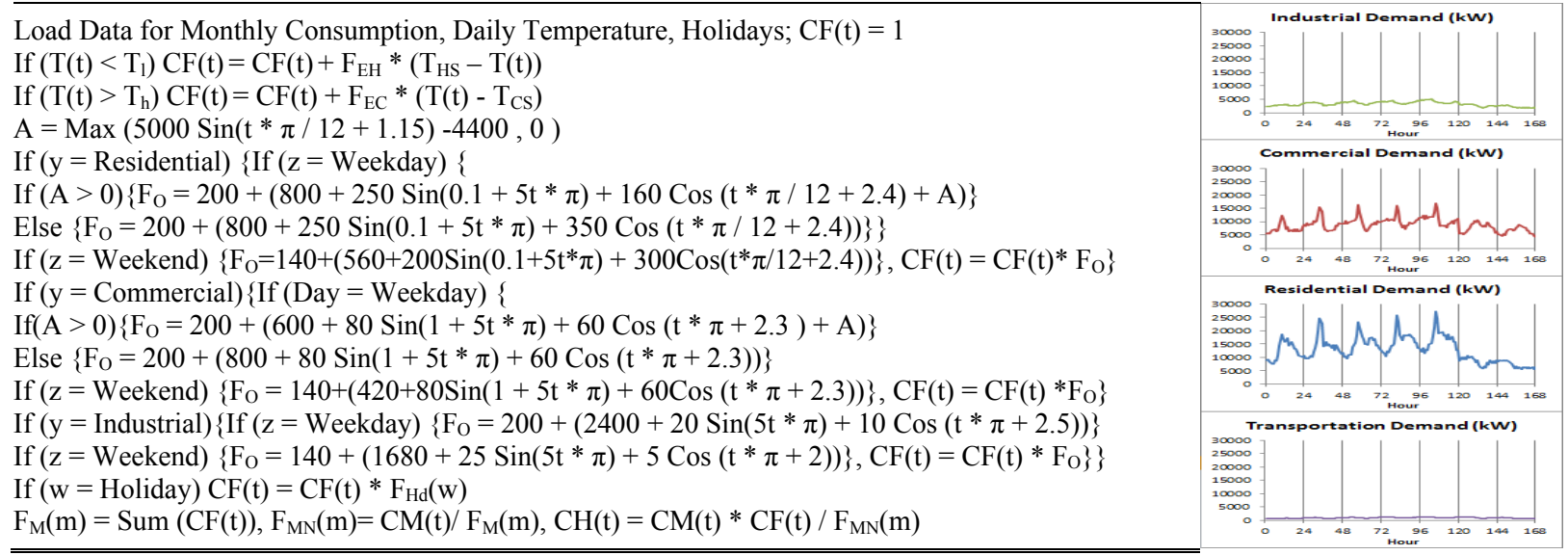

Figure 5: Algorithm 1 allocating hourly energy demand for the different sectors with exemplary plots

The energy demand module D has been implemented in Arena as shown in Figure 4. Here as entities arrive, they are assigned an amount of energy to be consumed according to Algorithm 1, and are routed to a step-down substation submodule. In this submodule, the energy demanding entities either use the energy from the grid, the storage systems, or are disposed if the demand cannot be met. If an entity is disposed it indicates that the current usage level of the energy generating systems is not adequate and the framework tries to trigger a mechanism to increase the operating level of the fossil fuel plants to full capacity. The scale up mechanism is constrained with a minimum downtime value similar to the one of the step up mechanism in module $\mathrm{S}$. These minimum values are imposed to module $\mathrm{D}$ and module $\mathrm{S}$ in order to consider the fact that fossil fuel energy generating plants take time to adjust their operational levels.

\subsection{Optimization Module (O)}

We developed module $\mathrm{O}$ to determine the parameters that lead to the best performance in cost and capacities of generation and storage systems, subject to the demand. Each time the optimization is called, it defines a candidate solution set of decision variables and enforces the simulation to evaluate the resulting performance for them. Based on the results, module $\mathrm{O}$ establishes a new candidate solution set of the decision variables and runs the simulation again, repeating the process until the results are satisfactory, or up to a preset number of runs. This simulation based optimization process provides precise results via the inclusion of near-optimal solution methods while including the uncertainty and randomness. In order to obtain the solutions from our optimization, we have employed the OptQuest tool. OptQuest automatically searches for optimal solutions in simulations by using a confluence of three different types of meta- 
heuristics including Scatter Search and Neural Networks, it's optimization procedure performs a "nonmonotonic search" that over time provides a highly efficient path to the best solutions.

The formulation of module $\mathrm{O}$ is given in (1)-(4) and has two objectives, minimization of overall costs of meeting energy demand, and minimization of the emission of pollutants generated as a consequence. The overall costs of meeting energy demand depend on the costs of energy generation and energy storage, each with separate time invariant and dependent components. The time invariant component depends on the rated capacity and base cost of each generating $\left(R_{i}^{G}\right)$ or storage $\left(R_{j}^{S}\right)$ facility, $\left(C_{i}^{G b}\right.$ and $\left.C_{j}^{S b}\right)$, and the fixed costs of operating them $\left(C_{i}^{G f}\right.$ and $\left.C_{j}^{S f}\right)$. The time dependent component is based on the electricity generated or stored by each facility over time $\left(E_{i t}^{G}\right.$ and $\left.E_{j t}^{S}\right)$ and by the fuel costs for operating them $\left(C_{i}^{G v}\right.$ and $\left.C_{j}^{S v}\right)$. The emission of pollutants depends on the amount of generated or stored electricity $\left(P_{i l}^{G}\right.$ and $\left.P_{j l}^{S}\right)$ and pollutants over time. An emissions tax $\left(T_{l}\right)$ is used for the amount of pollutants emitted. In addition, the energy demanded by each sector over time $\left(D_{k t}\right)$ must be fulfilled by the energy generating facilities and storage alternatives, up to a specified demand fulfillment factor $\left(D_{f f}\right)$. The rated capacity of energy generating and storage facilities have lower and upper limits $r l_{i}^{G}$ and $r l_{j}^{S}$, and $r u_{i}^{G}$ and $r u_{j}^{S}$, respectively.

$$
\begin{array}{cc}
\min \sum_{i=1}^{I} R_{i}^{G}\left(C_{i}^{G b}+C_{i}^{G f}\right)+\sum_{i=1}^{I} \sum_{t=1}^{T} E_{i t}^{G} C_{i}^{G v}+\sum_{j=1}^{J} R_{j}^{S}\left(C_{j}^{S b}+C_{j}^{S f}\right)+\sum_{j=1}^{J} \sum_{t=1}^{T} E_{j t}^{S} C_{j}^{S v} \\
\min \sum_{i=1}^{I} \sum_{t=1}^{T} \sum_{l=1}^{L} E_{i t}^{G} P_{i l}^{G} T_{l}+\sum_{j=1}^{J} \sum_{t=1}^{T} \sum_{l=1}^{L} E_{j t}^{S} P_{j l}^{S} T_{l} & \\
\text { Subject to } \quad D_{f f} \sum_{i=1}^{K} D_{k t} \leq \sum_{i=1}^{I} E_{i t}^{G}+\sum_{j=1}^{J} E_{j t}^{S} & \forall t \\
R_{i}^{G} \geq r l_{i}^{G}, R_{i}^{G} \leq r u_{i}^{G} \quad \forall i ; \quad R_{j}^{S} \geq r l_{j}^{S}, R_{j}^{S} \leq r u_{j}^{S} & \forall j
\end{array}
$$

Table 3 shows the costs of building and operating a power generating or storage facility. The base costs are incurred during the construction and are not recurrent. The project eventuality factor refers to provisions for unforeseeable events that will increase costs where these events have historically occurred in such projects (EIA 2010). The operational and maintenance costs are separated into variable and fixed costs, most variable costs are associated with fuel costs and thus are negligible for renewable technologies. Fixed costs cover indirect operational costs of the plant which do not change according to the facility's energy output, and may include costs such as the lease of the land where the facility is built, etc.

Table 3: Costs of building and operating a power generating or storage facility

\begin{tabular}{|c|c|c|c|c|c|}
\hline Technology & Base Costs $(\$ / \mathrm{kW})$ & Eventuality Factor & Total Base (\$/kW) & O\&M Variable (\$mills/kWh) & O\&M Fixed (\$/kW) \\
\hline Coal & 2,078 & 1.07 & 2,223 & 4.18 & 28.15 \\
\hline Combined Cycle & 897 & 1.08 & 969 & 14.77 & 11.96 \\
\hline Combustion Turbine & 617 & 1.05 & 648 & 80.11 & 10.77 \\
\hline Wind & 1,837 & 1.07 & 1,966 & 0 & 30.98 \\
\hline Photovoltaic & 5,879 & 1.05 & 6,173 & 0 & 11.94 \\
\hline CAES & 890 & 1.05 & 935 & 0 & 19 \\
\hline NaS Battery & 389 & 1.07 & 416 & 0 & 35 \\
\hline Pb Acid Battery & 540 & 1.05 & 567 & & 28 \\
\hline
\end{tabular}

\section{EXPERIMENTS AND RESULTS}

We have created a control form using VBA that enables the user to control the capacity of each energy generating and storage system, the yearly increases in demand for each sector, the GHG emission tax rates, the demand fulfillment factor and the planning horizon, shown in Figure 6. To evaluate the validity of the framework, we have designed a set of experiments with two main scenarios addressing the specifics of Florida with the inclusion and exclusion of a GHG emissions tax, with planning horizons from 3 years to 21 years. The major source of most emissions of GHG is fossil fuel energy production, and a way to address this issue is through the use of carbon taxes. A carbon tax tolls the $\mathrm{CO} 2$ emissions from fossil fuels, incentivizing the development of carbon-reducing measures such as energy efficiency, low-carbon fuels and renewable energy (Carbon Tax Center 2011). Various legislative bills have been introduced in the House of Representatives proposing the implementation of a carbon tax, including H.R. 594 (111th), and H.R. 2380 (111th). We use a carbon tax of \$10 per tonne of CO2, with yearly increments of $\$ 10$ per 
tonne. While proposals of taxes for the emissions of sulfur and NOx are not as common as for $\mathrm{CO} 2$, in our experiment a tax equal to the carbon tax is used for NOx and SOx emissions.

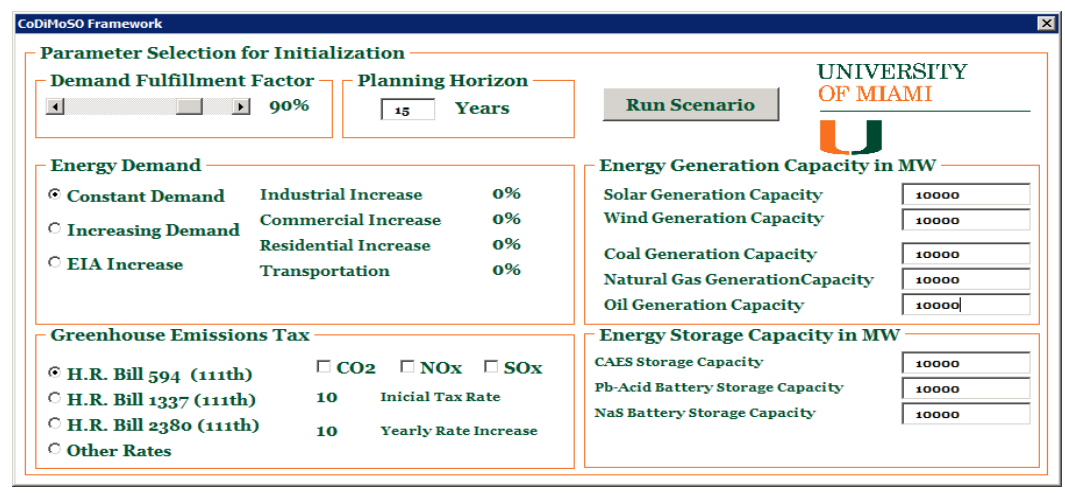

Figure 6: Simulation Control Form

Case 1 evaluates the total operational and investment costs, Case 2 incorporates the GHG emission taxes, Case 3 minimizes the GHG emissions, without considering operational costs. For each case, module $\mathrm{O}$ runs every planning horizon with 100 simulations, each of three replicates. This research has been conducted via extensive use of the Virtual Computing Facilities (Cloud) at UMIAC.

\subsection{Case 1: Cost Minimization with no Greenhouse Gas Emission Taxes}

We evaluate the total costs of fulfilling the energy demand of Florida with a fulfillment factor of 95\%, increases in energy demand and no GHG emissions tax. Figure 7 shows the average result of the 25 best feasible solutions, with a 95\% confidence interval (the blue line). The results show small variations in the performance, with half widths from $0.44 \%$ to $2.00 \%$ of the total cost. There is a change in the cost drivers from capital to variable costs after a planning horizon of 9 years. Renewable energy technologies are expected to be part of the optimal resource planning starting after this planning horizon. Table 4 shows the operational costs, and average generation and storage capacity for the 25 best feasible solutions suggested by module O. Annual operating costs decrease as the planning horizon increases, yet the decrease becomes smaller and will probably stabilize for planning horizon larger than 21 years.

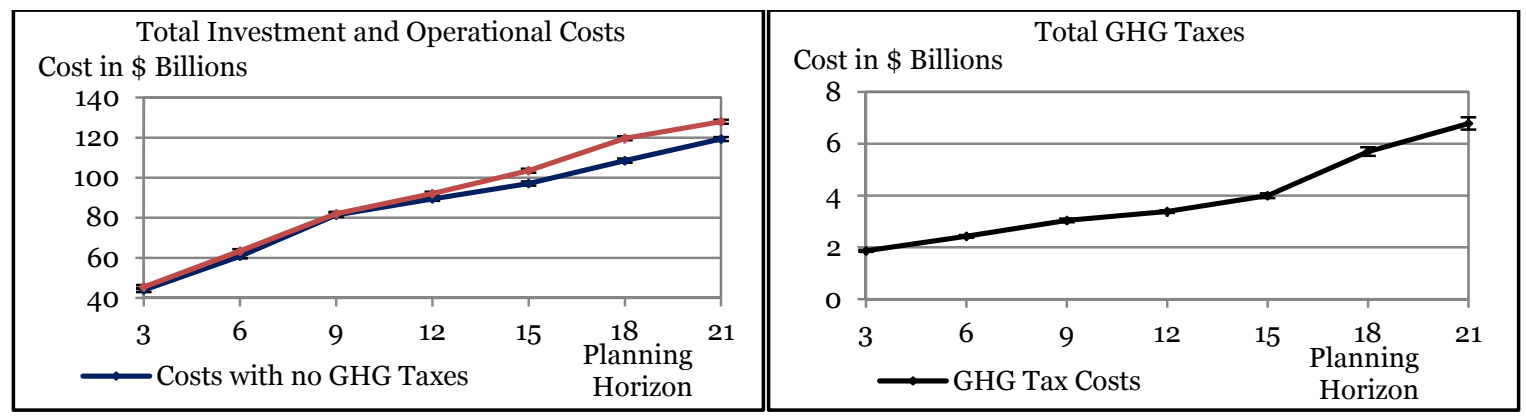

Figure 7: Comparison of total investment and operational costs with and without greenhouse gas emission taxes and minimum greenhouse gas emissions tax costs

The table evidences the shift in the cost drivers starting at a planning horizon of 12 years. For the short planning horizons, the optimal composition of energy generation has fossil fuel generation and energy storage capacities close to $98.6 \%$ and $5.5 \%$ of the total generation capacity. For the longer planning horizons, the composition of energy generating technologies includes renewable energy generation capacities that average $25.0 \%$ of the total generation, while the energy storage capacity is equal to $3.0 \%$ of the generation capacity; and the total energy generation capacity increases from an average capacity of $27.091 \mathrm{GW}$ for planning horizons up to 9 years to $35.127 \mathrm{GW}$ for horizons of 12 years or longer. The 
framework suggest energy storage is composed of $442.945 \mathrm{MW}$ of CAES, $312.435 \mathrm{MW}$ of Pb-Acid battery storage and $415.970 \mathrm{MW}$ of $\mathrm{NaS}$ battery storage, for a planning horizon of 21 years.

Table 4: Average costs, and energy generation and storage capacities

\begin{tabular}{|c|c|c|c|c|c|c|c|}
\hline Case & \begin{tabular}{|l} 
Planning \\
Horizon
\end{tabular} & $\begin{array}{l}\text { Avg. Costs } \\
\text { \$ Millions }\end{array}$ & $\begin{array}{l}\text { Avg. Annual Costs } \\
\text { \$ Millions }\end{array}$ & $\begin{array}{c}\text { Total Energy } \\
\text { Generation (MW) }\end{array}$ & $\begin{array}{c}\text { Fossil Fuel } \\
\text { Generation (MW) }\end{array}$ & $\begin{array}{c}\text { Renewable } \\
\text { Generation (MW) }\end{array}$ & $\begin{array}{c}\text { Storage } \\
\text { Capacity (MW) }\end{array}$ \\
\hline \multirow{7}{*}{$\begin{array}{l}\overrightarrow{0} \\
\tilde{J} \\
\tilde{U}\end{array}$} & 3 & 43,974 & 14,658 & 25,285 & 25,011 & 274 & 1,537 \\
\hline & 6 & 60,819 & 10,136 & 26,334 & 26,149 & 186 & 1,603 \\
\hline & 9 & 81,394 & 9,044 & 29,653 & 28,943 & 709 & 1,306 \\
\hline & 12 & 89,458 & 7,455 & 33,946 & 24,767 & 9,179 & 737 \\
\hline & 15 & 97,111 & 6,474 & 35,114 & 26,509 & 8,605 & 1,131 \\
\hline & 18 & 108,525 & 6,029 & 35,501 & 26,875 & 8,626 & 1,170 \\
\hline & 21 & 119,323 & 5,682 & 35,949 & 27,316 & 8,633 & 1,171 \\
\hline \multirow{7}{*}{ 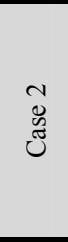 } & 3 & 45,480 & 15,160 & 25,285 & 25,011 & 274 & 1,537 \\
\hline & 6 & 63,367 & 10,561 & 26,273 & 26,091 & 183 & 1,601 \\
\hline & 9 & 81,998 & 9,111 & 27,666 & 26,947 & 719 & 1,657 \\
\hline & 12 & 92,080 & 7,673 & 33,958 & 24,825 & 9,132 & 762 \\
\hline & 15 & 103,529 & 6,902 & 35,114 & 26,509 & 8,605 & 1,131 \\
\hline & 18 & 119,679 & 6,649 & 37,581 & 29,429 & 8,152 & 1,118 \\
\hline & 21 & 127,931 & 6,092 & 33,793 & 27,286 & 6,507 & 1,047 \\
\hline \multirow{7}{*}{$\begin{array}{l}n \\
\tilde{J} \\
\tilde{z} \\
\tilde{J}\end{array}$} & 3 & 1,863 & 621 & 102,196 & 22,751 & 79,445 & 1,246 \\
\hline & 6 & 2,427 & 405 & 102,707 & 23,285 & 79,422 & 1,252 \\
\hline & 9 & 3,040 & 338 & 101,440 & 24,116 & 77,324 & 1,291 \\
\hline & 12 & 3,384 & 282 & 102,830 & 21,594 & 81,236 & 1,187 \\
\hline & 15 & 3,996 & 266 & 101,100 & 21,244 & 79,857 & 1,237 \\
\hline & 18 & 5,695 & 316 & 102,160 & 25,214 & 76,946 & 1,342 \\
\hline & 21 & 6,778 & 323 & 101,763 & 25,231 & 76,532 & 1,416 \\
\hline
\end{tabular}

\subsection{Case 2: Cost Minimization with Greenhouse Gas Emission Taxes}

Here we use the same conditions as in case 1 but including a GHG emissions tax. Figure 7 shows the average result of the 25 best feasible solutions, with a $95 \%$ confidence interval (the red line). In this case the results show variations in performance from the optimizers' 25 best feasible suggested solutions with half widths ranging from $0.40 \%$ up to $2.47 \%$ of the cost. Like the previous case, a shift from capital to operational costs as drivers of total cost is observed starting at a planning horizon of 12 years. For this case, Table 4 shows evidence of the shift in the cost drivers, starting at a planning horizon of 12 years. The optimal composition of energy generating technologies has fossil fuel energy generation and energy storage capacities close to $98.5 \%$ and $6.0 \%$ of the total generation capacity for the shorter planning horizons. For longer planning horizons, the composition of energy generation includes renewable energy generation capacities averaging $23.1 \%$ of the total generation, while the energy storage capacity is equal to $2.9 \%$ of the total generation capacity and the total energy generation capacity increases from an average capacity of $26.408 \mathrm{GW}$ for the planning horizons up to 9 years to $35.111 \mathrm{GW}$ for horizons of 12 or more years. The framework suggests storage composed of 214.168 MW of CAES, 438.101 MW of Pb-Acid battery storage and 395.309 MW of NaS battery storage. As fossil fuel generation is very close to $26.5 \mathrm{GW}$ in both cases 1 and 2, the inclusion of the GHG emission tax does not represent significant impacts on the composition of the capacity planning. Yet, it does lead to the inclusion of an extra $\$ 410$ million in annual operating costs, for a horizon of 21 years.

\subsection{Case 3: Emissions Taxes Minimization}

In this case we evaluate the GHG emissions tax costs with a fulfillment factor of $95 \%$ disregarding operational and investment costs. Figure 7 shows the average result of the twenty five best feasible solutions, with a $95 \%$ confidence interval (the black line). The optimization results show variations with half widths ranging from $1.54 \%$ up to $3.50 \%$ of the total cost. In this case the optimal composition of energy generating technologies has fossil fuel energy generation and energy storage capacities averaging $22.9 \%$ and $1.3 \%$ of the total generation capacity, with the total energy generation capacity having an average of 102.028 GW. In this case fossil fuel and renewable energy generation average $23.348 \mathrm{GW}$ and $78.68 \mathrm{GW}$ 
respectively, with storage composed of 978.422 MW of CAES, 122.581 MW of Pb-Acid battery storage and 180.434 MW of NaS battery storage. Without the consideration of investment or operational expenses, the suggested solution to fulfill $95 \%$ of Florida's energy demand incurs a cost of a GHG emissions taxes that averages $\$ 364$ million annually.

\section{CONCLUSIONS AND FUTURE WORK}

We have developed a comprehensive simulation based decision making framework to determine the best possible combination of investments for electric power generation and storage. This tool involves a combined continuous-discrete modular modeling approach for processes of different nature that exist within this complex system, and will help utility companies conduct resource planning via the employed multiobjective optimization techniques in a realistic simulation environment. The proposed approach has been successfully demonstrated for the electric utility planning at a scale of the state of Florida. In this case, for a planning horizon of 21 years, by incorporating a near optimal amount of energy storage of $1.17 \mathrm{GW}$, the energy demand may be met with a fulfillment factor of $95 \%$, with an energy generating capacity that averages $35.95 \mathrm{GW}$ (composed of $76 \%$ of fossil fuel and $24 \%$ of renewable energy generation). This is achieved at an average annual cost of $\$ 5.7$ billion. The implementation of a GHG emission tax has also been studied, the results have shown that the implementation of such a policy would conduce to an optimal energy storage of $1.05 \mathrm{GW}$ and energy generating capacity that averages $33.8 \mathrm{GW}$ (composed of $81 \%$ of fossil fuel and 19\% of renewable energy generation). This is achieved at an average annual cost of $\$ 6.1$ billion. Contrary to most common intuition, it neither significantly reduces the amount of fossil fuel energy generation nor increases the proportion of renewable energy generation due to the intermittency in generation from renewable energy sources, and the fact that the fossil fuel energy generating systems are used to ensure that base load demand is always met. This fact was evidenced when no operational or investment costs were considered and a fossil fuel energy generation capacity of $25.231 \mathrm{GW}$ is required. A GHG emission tax is redundant as the optimal planning capacity (that minimizes the operational costs) employs natural gas as its main fossil fuel energy generating system, since natural gas is the type of fossil fuel that has the lowest GHG emissions rate.

Future work of the proposed study extends to the incorporation of energy markets, energy pricing policies, and exhaustive experimentation for the identification of key technologies that have the greatest impact on the optimal resource planning financially, socially and ecologically.

\section{REFERENCES}

Akpinar, A., M. I. Komurcu, M. Kankal, I. H. Ozolcer, and K. Kaygusuz. 2007. "Energy Situation and Renewables in Turkey and Environmental Effects of Energy Use." Renewable and Sustainable Energy Review 12:2013-39.

Beaudin, M., H. Zareipour, A. Scellenbergable, and W. Resehart. 2010. "Energy Storage for Mitigating the Variability of Renewable Energy Sources." Energy for Sustainable Development 14(4): 302-314.

Carbon Tax Center. 2011. "Carbon Tax Center." Accessed February 3. www.carbontax.org.

Chen, H., Y. Cong, W. Yang, C. Tan, Y. Li, Y., and Y. Ding. 2009. "Progress in Electrical Energy Storage System: A Critical Review." Progress in Natural Science 19(3):291-312.

Dinçer, F. 2011. "The Analysis on Photovoltaic Electricity Generation Status, Potential and Policies of the Leading Countries in Solar Energy." Renewable and Sustainable Energy Reviews 15(1):713-720.

Dufo-Lopez, R., J. L. Bernal-Agustin, and J. A. Dominguez-Navarro. 2009. "Generation Management Using Batteries in Wind Farms: Economical and Technical Analysis for Spain.” Energy Policy 37(1):126-39.

Energy Information Administration (EIA). 2010. “Annual Energy Outlook 2011 Early Release Overview." Accessed December 13. www.eia.gov/forecasts/aeo/pdf/0383er\%282011\%29.pdf.

Energy Information Administration. 2010. “Annual Energy Review 2009.” Accessed January 13, 2011. www.eia.doe.gov/emeu/aer/pdf/aer.pdf. 
Sáenz Corredor, Celik, Asfour, and Son

Energy Information Administration. 2011. "Assumptions to the Annual Energy Outlook 2010 - Electricity MarketModule." Accessed January 13. www.eia.doe.gov/oiaf/aeo/assumption/electricity.html.

Erdogdu, E. 2009. "On the Wind Energy in Turkey." Renewable and Sustainable Energy Review 13: 1361-1371.

Eyer, J., J. Iannucci, and G. Corey. 2004. Energy Storage Benefits and Market Analysis Handbook. Technical Report SAND2004-6177, Sandia National Laboratories Albuquerque, New Mexico and Livermore, California.

Florida Power and Light (FPL). 2010. "Solar Projects." Accessed December 6. www.fpl.com/solar.

Florida Power and Light. 2008. "St. Lucie Wind Analysis Results." Accessed December 21, 2010. www.stluciewind.com/research/wind_results.pdf.

Florida Public Service Commission (FPSC). 2009. "2009 Statistics of the Florida Electric Utility Industry." Accessed January 27, 2011. www.psc.state.fl.us/utilities/electricgas/statistics/statistics-2009.pdf.

Gardner, J., and T. Haynes. 2007. Overview of Compressed Air Energy Storage. ER-07-001, Office of Energy Research, Policy and Campus Sustainability, Boise State University. Accessed January 27, 2011. http://coen.boisestate.edu/WindEnergy/resources/ER-07-001.pdf.

International Energy Agency (IEA). 2010. "Power generation from coal.” Accessed January 6, 2011. www.iea.org/papers/2010/power_generation_from_coal.pdf.

National Renewable Energy Lab (NREL). 2009. "Wind Research - Wind Integration Datasets." Accessed December 16, 2010. www.nrel.gov/wind/integrationdatasets.

Patel, M. R. 2006. Wind and Solar Power Systems: Design, Analysis, and Operation. Boca Raton, FL: Taylor \& Francis.

Siemens. 2010. "Press Releases.” Accessed January 4, 2011. www.siemens.com/press/en/pressrelease/ ?press=/en/pressrelease/2010/fossil_power_generation/efp201002037.htm

Skoplaki, E., and J. Palyvos. 2010. "Operating Temperature of Photovoltaic Modules: A Survey of Pertinent Correlations." Renewable Energy 34(1):23-29.

Succar, S., and R. H. Williams. 2008. "Compressed Air Energy Storage: Theory, Resources, and Applications for Wind Power." Princeton Environmental Institute Report.

WWEA (World Wind Energy Association). 2010. "World Wind Energy Report 2009." Accessed: December 21. http://www.wwindea.org/home/images/stories/worldwindenergyreport2009_s.pdf.

Zahedi, A. 2011. "Maximizing Solar PV Energy Penetration Using Energy Storage Technology." Renewable and Sustainable Energy Reviews 15(1):866-70.

\section{AUTHOR BIOGRAPHIES}

JUAN SÁENZ CORREDOR is a Ph.D. student in the Department of Industrial Engineering at the U. of Miami (UM). He received his B.S. in Industrial Engineering from the Universidad de los Andes in Colombia in 2007. His research interests are in adaptive modeling and control of distributed electricity power networks. He can be reached at j.saenz4@umiami.edu.

NURCIN CELIK is an Assistant Professor in the Department of Industrial Engineering at UM. She received her Ph. D. in Systems and Industrial Enginerring at U. of Arizona. She has received several awards such as the IAMOT 2011 Outstanding Research Project Award and the IIE 2009 Outstanding Graduate Research Award. Her interests are in modeling and control of dynamic, complex, and large scale systems and supply chains with a focus on particle filtering methods. She can be reached at celik@miami.edu.

SHIHAB ASFOUR is a Professor and the Associate Dean for Academics of the College of Engineering at UM. His research interests are in statistics of energy conservation. He received several awards including the IIE Fellow and Jones Outstanding Mentor Awards. He can be reached at sasfour@miami.edu.

YOUNG-JUN SON is an Associate Professor of Systems and Industrial Engineering at U. of Arizona. He has received the SME 2004 Outstanding Young Manufacturing Engineer Award, and the IIE 2005 Outstanding Young Industrial Engineer Award. He can be reached by email at son@sie.arizona.edu. 